CLINICAL STUDY

\title{
Renal stones and calcifications in patients with primary hyperparathyroidism: associations with biochemical variables
}

\author{
Jakob Starup-Linde*, Elin Waldhauer*, Lars Rolighed ${ }^{1}$, Leif Mosekilde and Peter Vestergaard \\ The Osteoporosis Clinic, Department of Endocrinology and Internal Medicine (MEA) and ${ }^{1}$ Department of Surgery P, Aarhus University Hospital THG, Tage \\ Hansens Gade 2, DK-8000 Aarhus, Denmark
}

(Correspondence should be addressed to P Vestergaard; Email: p-vest@post4.tele.dk)

*(J Starup-Linde and E Waldhauer contributed equally to this work)

\begin{abstract}
Objective: To study the prevalence of renal stones and nephrocalcinosis in patients with primary hyperparathyroidism (PHPT) and to appraise biochemical variables as risk factors for developing renal calcifications.

Design: Cross-sectional.

Materials and methods: All patients $(n=177)$ undergoing diagnostic evaluation and surgery for PHPT at Aarhus University Hospital between 2007 and 2009. All patients underwent routine spiral CT scans of the abdomen to determine the presence or absence of renal calcifications.

Results: A total of 45 patients $(25.4 \%$, 95\% confidence intervals: $19.0-31.4 \%)$ had renal stones $(15.3 \%)$ and/or renal calcifications $(10.2 \%)$ on the CT scans. Compared with those without calcification $(n=132)$, the group with calcification had a significantly lower plasma creatinine level $(67.0 \pm 25.1$ vs $74.6 \pm 17.5 \mu \mathrm{mol} / \mathrm{l}, 2 P=0.03)$. Moreover, CaE was higher in PHPT patients with renal calcification than in PHPT patients without $(0.91 \pm 0.28 \mathrm{vs} 0.74 \pm 0.40 \mathrm{mmol} / \mathrm{mmol}$, $2 P=0.02$ ). The other measured or derived biochemical variables were similar in the two groups. No biochemical variable was predictive for renal calcifications in a multiple regression analysis.

Conclusion: We found a high prevalence of renal calcifications among PHPT patients but no deterioration of renal function. The occurrence of calcifications was related to low plasma creatinine and a high urine calcium/creatinine ratio. However, biochemical markers in general were poor predictors for the risk of renal stones or nephrocalcinosis indicating that routine image diagnostics may be needed for the identification of these complications in order to establish indication for surgery and ensure proper treatment.
\end{abstract}

European Journal of Endocrinology 166 1093-1100

\section{Introduction}

Primary hyperparathyroidism (PHPT) is a common disease with a population prevalence traditionally estimated to be $0.1-0.4 \%(1,2,3)$, previously estimated to be $0.1-0.4 \%(2,4)$ and recently up to $0.7 \%(5,6)$. The diagnostic incidence has increased considerably after the introduction of multichannel biochemistry. Nowadays, PHPT is often diagnosed by chance in relation to biochemical screening, primarily in middle-aged to elderly patients with subtle or nonspecific symptoms (7). PHPT is caused by a monoclonal parathyroid adenoma $(85-90 \%)$ or by multiglandular hyperplasia $(10-15 \%)$ and is characterised by increased circulating parathyroid hormone (PTH) levels in spite of hypercalcaemia (2). The elevated PTH levels are related to a shift in the set point of calciumregulated PTH secretion. This means that the normal inverse sigmoid relationship between PTH and calcium still exists, but the curve is shifted to the right so that higher plasma calcium levels are needed to suppress PTH $(8,9)$.

The elevated PTH increases plasma and urinary calcium in several ways. In the kidneys, PTH stimulates the renal tubular reabsorption of calcium (TRCa\%) (8). However, in spite of the increased reabsorption, the renal calcium excretion is typically increased due to an increased filtered load (10). In the bones, the PTH elevates plasma calcium by promoting osteoclastic bone resorption $(9,11)$ and possibly also by enhancing the active transport of calcium over the bone-extracellular fluid barrier mediated by osteocytes and lining cells (12). PTH also increases the renal production of calcitriol $\left(1,25(\mathrm{OH})_{2} \mathrm{D}\right)$ by activating the enzyme 250HD-1 $\alpha$-hydroxylase $(13,22)$. Finally, calcitriol stimulates the intestinal calcium absorption (14) and to some extent promotes the renal TRCa\% (15). In addition, PTH decreases the renal tubular reabsorption of phosphate (8), whereas calcitriol increases intestinal phosphate absorption (10). 
The aetiology of renal stones is multifactorial; however, hypercalciuria is considered to be one of the primary risk factors (16). In accordance, PHPT is a known risk factor for renal stone formation, which is observed with an estimated prevalence of $7-40 \%$ $(17,18)$. Furthermore, among patients presenting with renal stones, the prevalence of concurrent PHPT is around $2 \%(19)$. However, the precise relationship between the clinical presentation of PHPT and the increased formation of renal stones is not completely understood as only some (20), but not all $(19,21)$ studies have shown an increased renal calcium excretion in PHPT patients with renal stones. Young age at the time of diagnosis $(17,20,21,22,23,24)$ and male gender $(17,20,23,25)$ have often been associated with renal stones, whereas divergent results have been reported for other variables including parathyroid pathology $(17,21,22,23,26,27)$, plasma calcium $(17,20,21,22,23,27)$, plasma PTH $(17,20,22,27)$, plasma calcitriol $(13,17,27)$, diuresis $(17,26)$ and other biochemical variables such as urinary citrate $(17,26)$. To prevent stone formation in the urinary tract, there are inhibitors and among these citrate is the most important. In PHPT, calcium binds to citrate and lowers the urinary tract's defence against stone formation (28).

\section{Aim of the study}

We aimed at investigating the present prevalence of renal calcification among patients operated for PHPT who had a routine spiral CT investigation performed and to explore the possible differences in demographic and biochemical variables between patients with renal calcification and patients without. In this study, renal calcification is defined as both renal stones (stones in the urinary tract) and nephrocalcinosis (presence of calcification in the renal tissue).

\section{Materials and methods}

All patients who are suspected of having PHPT (DE210) in the Central Jutland Region of Denmark are referred to the University Department of Medical Endocrinology and Internal Medicine (MEA) at the Aarhus University Hospital where the indication for surgery is decided based on symptoms, complications and feasibility in collaboration with the surgeons. A small proportion of patients (around 5\%) are referred directly to surgery from other regional hospitals. Approximately $95 \%$ of the patients underwent surgery for their condition at the neighbouring Department of Surgery. We performed the current investigation as a cross-sectional study using a historic cohort of PHPT patients consecutively referred during the period 2007-2009. CT scans are a routine procedure in our clinic. All patients gave consent for the examinations. Owing to lack of consent, some patients do not undergo CT scans. As the study was a retrospective study, no approval from the Ethical Committee was needed under Danish law. The total cohort included originally 311 PHPT patients who had undergone parathyroid surgery (code KBBA 0099). All patients were included in this cohort irrespective of symptoms or severity of disease. However, from this cohort, we excluded 43 patients with wrong operation codes and parathyroid implantations (KBBA70), 68 because of lack of spiral CT scans due to various reasons (previous ultrasound investigation or CT scan at referring hospital, refusal, no appearance or administrative errors) and 23 for other reasons: hypercalcaemia caused by chronic renal disease (tertiary hyperparathyroidism) (29), biochemical variables could not be retrieved (29), and errors in entry of central personal registration number (13)). Patients with familial hypocalciuric hypercalcaemia $(\mathrm{FHH})$ were eliminated based on a low calcium/creatinine clearance ratio and evidence of inactivating mutations of the CASR gene (30). After exclusion (Fig. 1), the study consisted of 177 hypercalcaemic patients with a mean of two to four calcium measurements and plasma intact PTH in the upper one-third of the normal range or elevated (P-PTH $>5 \mathrm{pmol} / \mathrm{l})$ (31). The patients were then divided into two groups, with or without renal calcification on spiral CT scan, and the blood and urine samples were compared. No patients had both renal stones and nephrocalcinosis.

\section{Methods}

As a part of routine diagnostic work-up, almost all our patients had a spiral CT scan (Philips Mx8000) of the abdomen, performed to confirm or disprove the presence of renal calcification. CT findings were subdivided into frank renal stones located in calyces, pelvis and ureters

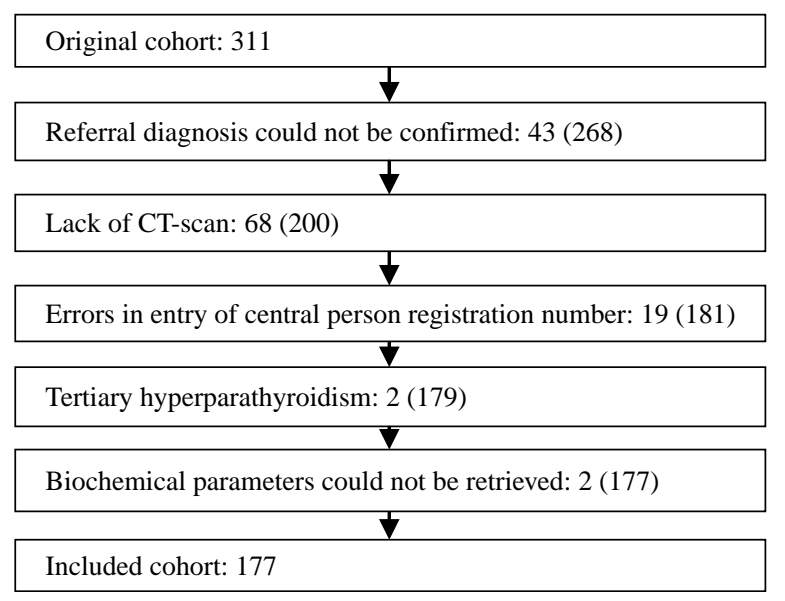

Figure 1 Study flowchart showing the number of patients excluded for various reasons. Figures in brackets give the number of remaining patients. 
and nephrocalcinosis with calcifications of the renal tissue but no calcifications in the urinary tract system. As a routine, we measured plasma and 24-h urine calcium and creatinine, and plasma $\mathrm{Ca}^{2+}$, albumin, creatinine, phosphate and alkaline phosphatase by standard laboratory methods. We determined plasma intact PTH using the second-generation Elecsys 2010 immunoassay (Roche Diagnostics). The interassay coefficients of variation $(\mathrm{CV})$ were $<6 \%$. We measured plasma 250HD levels by isotope dilution liquid chromatography-tandem mass spectrometry using calibrators traceable to NIST $>$ SRM 972. The interassay precision was 9.4 and $8.8 \%$ at 32.0 and $59.7 \mathrm{nmol} / \mathrm{l}$ respectively, for $25 \mathrm{OHD}_{3}$ and 8.6 and $8.0 \%$ at 23.4 and $64.4 \mathrm{nmol} / \mathrm{l}$ respectively, for $25 \mathrm{OHD}_{2}$. The detection limit was $10 \mathrm{nmol} / \mathrm{l}$ for both metabolites (32). We measured plasma $1,25(\mathrm{OH})_{2} \mathrm{D}$ by RIA (IDS) with interassay CV from 11 to $18 \%$ at plasma levels from 18 to $111 \mathrm{pmol} / \mathrm{l}$. The renal excretion of cross-linked $\mathrm{N}$ terminal telopeptide of type 1 collagen $(\mathrm{NTx} /$ creatinine ratio) was quantified by ELISA on the second void morning urine using an automated instrument (Vitros ECI; Ortho Clinical Diagnostics, Amersham, UK). The NTx CV was between 4.7 and $8.5 \%$ at urine levels at 73-541 nmol BCE/mmol creatinine. All biochemical analyses were performed in an ISO standardised laboratory (Department of Clinical Biochemistry, Aarhus University Hospital) with daily quality control procedures. From plasma and urine variables, we calculated the renal creatinine clearance $(\mathrm{ml} / \mathrm{min})$, the renal calcium/creatinine excretion ratio (CaE $\mathrm{mmol} / \mathrm{mmol}$ ) and the renal TRCa $\%$.

For each variable mean value, S.D. and 95\% confidence intervals (CIs) were calculated, and they were compared by $t$-tests or $F$-test as appropriate. A mutually adjusted multivariate logistic regression analysis was performed to identify potential predictors of presence of renal calcifications. Significance level was $P \leq 0.05$. All calculations were performed using Microsoft Excel and IBM SPSS 19.0 (SPSS Inc., Chicago, IL, USA).

\section{Results}

Among the 177 patients, postoperative pathological examinations revealed parathyroid adenomas in 91\% of the patients and hyperplasia in $9 \%$ of the patients. In total, 45 had spiral CT-confirmed renal stones $(n=27)$ or nephrocalcinosis $(n=18)$ while 132 did not, yielding a total prevalence of renal calcifications of 25.4\%, 95\% CIs 19.0-31.9\% (Table 1).

The average p-creatinine values were within the normal range in both the groups, but patients

Table 1 Demographic and biochemical characteristics of 177 patients referred for primary hyperparathyroidism during the period 20072009 who had a routine spiral CT investigation performed to diagnose renal calcification including renal stones and nephrocalcinosis.

\begin{tabular}{|c|c|c|c|c|c|c|c|c|c|c|c|}
\hline \multirow[b]{2}{*}{ Variable } & \multirow{2}{*}{$\begin{array}{l}\text { Reference } \\
\text { range }\end{array}$} & \multicolumn{3}{|c|}{ All patients } & \multicolumn{3}{|c|}{$\begin{array}{l}\text { Patients without } \\
\text { calcifications }\end{array}$} & \multicolumn{3}{|c|}{$\begin{array}{l}\text { Patients with } \\
\text { calcifications }\end{array}$} & \multirow[b]{2}{*}{$2 P^{\mathrm{a}}$} \\
\hline & & $n$ & $x$ & S.D. & $n$ & $x$ & S.D. & $n$ & $x$ & S.D. & \\
\hline \multicolumn{12}{|l|}{ Demography } \\
\hline Gender (males/females) & & & & & $26 / 106$ & & & $8 / 37$ & & & 0.97 \\
\hline Age (years) & & 177 & 62.0 & 12.3 & 132 & 62.1 & 12.5 & 45 & 59.9 & 11.1 & 0.31 \\
\hline Height $(\mathrm{cm})$ & & 119 & 166.2 & 8.9 & 84 & 165.9 & 8.8 & 35 & 167.1 & 9.2 & 0.50 \\
\hline Body weight (kg) & & 119 & 78.3 & 16.2 & 84 & 75.9 & 16.3 & 35 & 73.7 & 16.2 & 0.49 \\
\hline BMI $\left(\mathrm{kg} / \mathrm{m}^{2}\right)$ & & 119 & 27.2 & 5.2 & 84 & 27.5 & 5.1 & 35 & 26.4 & 5.2 & 0.28 \\
\hline \multicolumn{12}{|l|}{ Plasma } \\
\hline P-ionised calcium (mmol/l) & $1.15-1.30$ & 177 & 1.47 & 0.13 & 132 & 1.46 & 0.12 & 45 & 1.49 & 0.17 & 0.27 \\
\hline P-phosphate $(\mathrm{mmol} / \mathrm{l})$ & $0.80-1.50$ & 160 & 0.84 & 0.19 & 118 & 0.86 & 0.19 & 42 & 0.80 & 0.19 & 0.08 \\
\hline P-creatinine $(\mu \mathrm{mol} / \mathrm{l})$ & $50-100$ & 177 & 73.2 & 23.1 & 132 & 74.6 & 25.1 & 45 & 67.0 & 17.5 & 0.03 \\
\hline P-PTH (pmol/l) & $1.6-6.9$ & 177 & 14.2 & 8.73 & 132 & 13.6 & 6.99 & 45 & 16.2 & 12.4 & 0.19 \\
\hline P-calcitriol (pmol/l) & $60-180$ & 163 & 177 & 71.5 & 124 & 171.6 & 69.3 & 39 & 195.4 & 76.3 & 0.07 \\
\hline $\mathrm{P}-25 \mathrm{OHD}(\mathrm{nmol} / \mathrm{l})$ & $50-160$ & 174 & 69.5 & 30.7 & 130 & 70.2 & 32.0 & 44 & 67.6 & 26.8 & 0.63 \\
\hline P-alkaline phosphatase (U/I) & $35-105$ & 112 & 88.0 & 28.8 & 79 & 86.1 & 27.1 & 33 & 89.9 & 28.2 & 0.50 \\
\hline \multicolumn{12}{|l|}{ Urine } \\
\hline $\begin{array}{l}\text { U-NTx/creatinine } \\
(((\mathrm{nmol} / \mathrm{l}) /(\mathrm{mmol} / \mathrm{l}))\end{array}$ & & 19 & 66.8 & 42.3 & 13 & 65.5 & 38.1 & 6 & 47.5 & 36.4 & 0.35 \\
\hline 24-h urine calcium (mmol) & $2.0-9.0$ & 136 & 7.7 & 3.58 & 103 & 7.44 & 3.7 & 33 & 8.49 & 3.1 & 0.14 \\
\hline 24-h urine creatinine (mmol) & $6.0-22.0$ & 111 & 9.9 & 3.81 & 82 & 9.83 & 3.33 & 29 & 10.3 & 4.99 & 0.60 \\
\hline \multicolumn{12}{|l|}{ Derived variables } \\
\hline Creatinine clearance $(\mathrm{ml} / \mathrm{min})$ & $70-150$ & 111 & 101 & 41.0 & 82 & 96.7 & 33.6 & 29 & 113.0 & 56.1 & 0.07 \\
\hline Ratio $\mathrm{Ca}_{\mathrm{E}}(\mathrm{mmol} / \mathrm{mmol})$ & $0.05-0.80$ & 109 & 0.78 & 0.38 & 82 & 0.74 & 0.40 & 27 & 0.91 & 0.28 & 0.02 \\
\hline $\mathrm{TRCa} \%$ & $97.5-98.7$ & 108 & 95.3 & 13.2 & 82 & 94.8 & 15.1 & 26 & 97.0 & 1.02 & 0.19 \\
\hline
\end{tabular}

$25 \mathrm{OHD}$, all year 25-hydroxyvitamin D; 1,25(OH) 2 D, 1,25dihydroxyvitamin D; PTH, parathyroid hormone; AP, total alkaline phosphatase; NTx/creatinine, urine amino-terminal telopeptide of collagen cross link to creatinine ratio; $\mathrm{Cr}$ clearance, creatinine clearance, $\mathrm{Ca}_{\mathrm{E}}, 24-\mathrm{h}$ urine calcium to creatinine ratio; TRCa\%, rental tubular reabsorption of calcium in percentage of filtered calcium.

${ }^{\mathrm{a} C}$ Comparing patients with and without calcification. 
with renal calcification had lower p-creatinine $(67.0 \pm 17.5 \mu \mathrm{mol} / \mathrm{l})$ than patients without renal calcifications $(74.6 \pm 25.1 \mu \mathrm{mol} / \mathrm{l}, \quad P<0.03)$. They also tended to have a borderline better renal function as measured by creatinine clearance, although the difference was not significant $(96.7 \pm 33.6$ vs 113.0 $\pm 56.1 \mathrm{ml} / \mathrm{min}, P<0.07)$. The two groups had the same degree of elevated plasma PTH, hypercalcaemia and hypercalciuria expressed as excreted calcium $/ 24 \mathrm{~h}$. In total, $24 \%$ of those with plasma $\mathrm{Ca}^{2+} \leq 1.45 \mathrm{mmol} / \mathrm{l}$ had either renal stones or nephrocalcinosis compared with $26 \%$ of those with plasma $\mathrm{Ca}^{2+}>1.45 \mathrm{mmol} / \mathrm{l}$ $(P=0.70)$.

The renal calcium/creatinine excretion ratio ( $\mathrm{CaE} \mathrm{mmol} / \mathrm{mmol}$ ) was higher in PHPT patients with renal calcifications than in PHPT patients without $(0.91 \pm 0.28$ vs $0.74 \pm 0.40 \mathrm{mmol} / \mathrm{mmol}, P=0.02)$. However, the power to predict calcifications was low with a partial squared correlation coefficient of only 0.08. In an overlap performance analysis, it did not seem that a cut-off level for $\mathrm{CaE}$ existed below which renal stones did not form.

The renal TRCa\% did not differ between groups, neither did plasma phosphate $(0.86 \pm 0.19$ vs 0.80 $\pm 0.19 \mathrm{mmol} / \mathrm{l}, P<0.08$ ).

The two groups had equal plasma $250 \mathrm{HD}$ levels with mean values and CIs within the normal range. In contrast, plasma $1,25(\mathrm{OH})_{2} \mathrm{D}$ levels were increased compared with the reference range in $41.1 \%, 95 \% \mathrm{CI}$ $33.5-49.1 \%$, of the patients. Stone formers had insignificantly $(P<0.07)$ higher plasma $1,25(\mathrm{OH})_{2} \mathrm{D}$ levels, 195 (95\% CI 171-219) pmol/l, than non-stone formers, $172(159-184) \mathrm{pmol} / \mathrm{l}$, but the difference was not significant $(P<0.07)$.

Table 2 shows a mutually adjusted multivariate logistic regression analysis of biochemical variables vs presence or absence of renal calcifications. In the

Table 2 Mutually adjusted logistic regression analysis of biochemical variables vs presence or absence of renal calcifications in 177 patients with primary hyperparathyroidism.

\begin{tabular}{lcc}
\hline & $\begin{array}{c}\text { Partial regression } \\
\text { coefficient } \\
\text { Variable }\end{array}$ & \\
\hline Gender & $-0.14 \pm 0.93$ & $\boldsymbol{P}$ \\
Age & $-0.01 \pm 0.02$ & 0.88 \\
Plasma Ca ${ }^{2+}$ & $-2.63 \pm 3.38$ & 0.93 \\
Plasma phosphate & $-0.13 \pm 1.78$ & 0.44 \\
Plasma creatinine & $0.02 \pm 0.02$ & 0.94 \\
Plasma PTH & $-0.03 \pm 0.05$ & 0.31 \\
Plasma calcitriol & $-0.004 \pm 0.005$ & 0.56 \\
Plasma 25OHD & $-0.01 \pm 0.01$ & 0.35 \\
Plasma alkaline phosphatase & $-0.01 \pm 0.01$ & 0.27 \\
Urine calcium & $-0.2 \pm 0.1$ & 0.17 \\
Urine creatinine & $0.02 \pm 0.01$ & 0.22 \\
\end{tabular}

25OHD, 25-hydroxyvitamin D; PTH, parathyroid hormone. adjusted model, none of the variables were predictive of renal calcifications.

A direct comparison of patients with renal stones and patients with nephrocalcinosis without renal stones disclosed no significant differences between the two groups concerning gender, height, body mass index (BMI) or biochemical variables (Table 3). However, the mean age was lower in patients with renal stones than in patients with nephrocalcinosis $(57.7 \pm 12.2$ vs $64.8 \pm 7.4$ years, $P=0.03)$. Furthermore, in a mutually adjusted logistic regression analysis, none of the included biochemical variables could predict the nature of the observed calcifications (Table 4). Inclusion of age, gender and BMI did not change these results.

\section{Discussion}

We found the prevalence of renal calcification among operated PHPT patients on CT imaging to be $25.4 \%$ (95\% CI 19.0-31.9\%). This is in contrast to the findings of Odvina et al. (17) who reported a frequency of $60 \%$ found by a history of passing stone, removal of stone or roentgenogram. They retrieved data from 131 patients aged $\geq 18$ years and diagnosed with PHPT by hypercalcaemia, high PTH levels and no secondary cause of hyperparathyroidism. They excluded patients with moderate-severe diarrhoea syndrome and impaired renal function. Our findings are also in contrast to the prevalence of $7 \%$ found by routine renal sonography by Suh et al. (18). They retrospectively investigated 271 with surgically proven parathyroid adenomas. Berger et al. (26) found a prevalence of $20 \%$ based on the history of patient reporting of stone passage and previous stone-related procedures. They examined 54 symptomatic patients with PHPT at a referral centre for parathyroid surgery who completed 24-h preoperative urine collection. In addition, Bandeira et al. (29) found a prevalence of renal stones among PHPT-diagnosed patients to be $45 \%$ based on 22 patients and giving no information on how they diagnosed renal stone. We would have expected a lower prevalence than that in previous studies because of the earlier diagnosis and treatment of PHPT in recent times. Taking into account that the study of Odvina et al. (17) also includes the history of previous stones, our study suggests that the prevalence of stones has not decreased. It also points to the importance of including previous stones in the evaluation of risk of stones in PHPT. Our prevalence of renal calcification was higher than the prevalence reported based on sonography (18). This may suggest that a CT scan in a cross-sectional setting is more sensitive than sonography in the diagnosis of nephrocalcinosis and should be used for the routine examination of the patients. It is difficult to conclude on the prevalence of renal stones in PHPT as the reports vary from $7 \%$ (18) to $60 \%$ (17). The wide range in reported prevalence of stones is difficult to 
Table 3 Demographic and biochemical characteristics of 45 patients referred for primary hyperparathyroidism during the period 20072009 who either had positive renal stones or nephrocalcinosis documented by a routine spiral CT investigation.

\begin{tabular}{|c|c|c|c|c|c|c|c|c|c|c|c|}
\hline \multirow[b]{2}{*}{ Variable } & \multirow{2}{*}{$\begin{array}{l}\text { Reference } \\
\text { range }\end{array}$} & \multicolumn{3}{|c|}{$\begin{array}{l}\text { Patients without } \\
\text { calcifications }\end{array}$} & \multicolumn{3}{|c|}{$\begin{array}{l}\text { Patients with renal } \\
\text { stones }\end{array}$} & \multicolumn{3}{|c|}{$\begin{array}{c}\text { Patients with } \\
\text { nephrocalcinosis }\end{array}$} & \multirow[b]{2}{*}{$2 P^{a}$} \\
\hline & & $n$ & $x$ & S.D. & $n$ & $x$ & S.D. & $n$ & $x$ & S.D. & \\
\hline \multicolumn{12}{|l|}{ Demography } \\
\hline Gender (males/females) & & $26 / 106$ & & & $6 / 21$ & & & $2 / 16$ & & & 0.53 \\
\hline Age (years) & & 132 & 62.1 & 12.5 & 27 & 57.7 & 12.2 & 18 & 64.8 & 7.4 & 0.28 \\
\hline Height $(\mathrm{cm})$ & & 84 & 165.9 & 8.8 & 22 & 167.4 & 7.8 & 14 & 167.0 & 11.2 & 0.66 \\
\hline Body weight $(\mathrm{kg})$ & & 84 & 75.9 & 16.3 & 22 & 71.2 & 14.3 & 14 & 77.1 & 18.2 & 0.82 \\
\hline BMI $\left(\mathrm{kg} / \mathrm{m}^{2}\right)$ & & 84 & 27.5 & 5.1 & 22 & 25.5 & 4.8 & 14 & 27.6 & 5.7 & 0.99 \\
\hline \multicolumn{12}{|l|}{ Plasma } \\
\hline P-ionised calcium (mmol/l) & $1.15-1.30$ & 132 & 1.46 & 0.12 & 27 & 1.48 & 0.16 & 18 & 1.51 & 0.18 & 0.28 \\
\hline P-phosphate $(\mathrm{mmol} / \mathrm{l})$ & $0.80-1.50$ & 118 & 0.86 & 0.19 & 26 & 0.81 & 0.18 & 16 & 0.78 & 0.21 & 0.12 \\
\hline P-creatinine $(\mu \mathrm{mol} / \mathrm{l})$ & $50-100$ & 132 & 74.6 & 25.1 & 27 & 64.8 & 16.5 & 18 & 70.3 & 18.9 & 0.40 \\
\hline P-PTH (pmol/l) & $1.6-6.9$ & 132 & 13.6 & 6.99 & 27 & 16.5 & 13.1 & 18 & 15.7 & 11.7 & 0.47 \\
\hline P-calcitriol $(\mathrm{pmol} / \mathrm{l})$ & $60-180$ & 124 & 171.6 & 69.3 & 23 & 193.4 & 86.0 & 16 & 198.2 & 62.5 & 0.15 \\
\hline P-25OHD (nmol/l) & $50-160$ & 130 & 70.2 & 32.0 & 26 & 71.5 & 26.7 & 18 & 61.9 & 26.8 & 0.30 \\
\hline P-alkaline phosphatase (U/I) & $35-105$ & 79 & 86.1 & 27.1 & 23 & 95.0 & 27.9 & 14 & 83.4 & 25.1 & 0.67 \\
\hline \multicolumn{12}{|l|}{ Urine } \\
\hline $\begin{array}{l}\text { U-NTx/creatinine } \\
\text { (nMemolBCE/mmol) }\end{array}$ & & 13 & 65.5 & 38.1 & 2 & 67.0 & 62.2 & 5 & 55.6 & 44.7 & 0.52 \\
\hline 24-h urine calcium (mmol) & $2.0-9.0$ & 103 & 7.44 & 3.7 & 20 & 8.38 & 2.55 & 13 & 8.67 & 3.91 & 0.27 \\
\hline 24-h urine creatinine (mmol) & $6.0-22.0$ & 82 & 9.83 & 3.33 & 18 & 10.8 & 6.02 & 11 & 9.36 & 2.57 & 0.66 \\
\hline \multicolumn{12}{|l|}{ Derived variables } \\
\hline Creatinine clearance $(\mathrm{ml} / \mathrm{min})$ & $70-150$ & 82 & 96.7 & 33.6 & 18 & 116.9 & 60.9 & 11 & 106.6 & 49.5 & 0.54 \\
\hline Ratio $\mathrm{Ca}_{\mathrm{E}}(\mathrm{mmol} / \mathrm{mmol})$ & $0.05-0.80$ & 82 & 0.74 & 0.40 & 18 & 0.85 & 0.27 & 9 & 1.01 & 0.27 & 0.052 \\
\hline $\mathrm{TRCa} \%$ & $97.5-98.7$ & 82 & 94.8 & 15.1 & 17 & 97.1 & 1.00 & 9 & 96.8 & 1.07 & 0.25 \\
\hline
\end{tabular}

*Significantly different from patients without calcification, $2 P<0.01$. 25OHD, all year 25-hydroxyvitamin $\mathrm{D} ; 1,25(\mathrm{OH})_{2} \mathrm{D}, 1,25$ dihydroxyvitamin $\mathrm{D} ; \mathrm{PTH}$, parathyroid hormone; AP, total alkaline phosphatase; NTx/creatinine, urine amino-terminal telopeptide of collagen cross link to creatinine ratio; Cr clearance, creatinine clearance; $\mathrm{Ca}_{\mathrm{E}}, 24-\mathrm{h}$ urine calcium to creatinine ratio; TRCa\%, rental tubular reabsorption of calcium in percentage of filtered calcium

${ }^{a}$ Comparing patients with renal stones and patients with nephrocalcinosis.

explain but may be based on the differences between studies in study populations, assessment of previous clinical stones and methodology used to identify calcifications and persistent stones. It is noteworthy that in our study, none of the biochemical parameters were predictive of presence of renal calcifications in an unadjusted model except for plasma creatinine and the renal calcium/creatinine clearance rate (CaE).

No association between serum calcium levels and prevalence of renal stones or nephrocalcinosis was present. It thus did not change the estimates to present the data separately according to the severity of the disease. This is a key finding, as it shows that even among patients with seemingly mild disease, the prevalence of renal calcifications may be high.

We found a significantly lower p-creatinine among PHPT patients with renal calcifications, especially in those with renal stones compared with non-stone formers. This finding suggests that the renal stones have not damaged the renal function. The lower plasma creatinine levels among patients with renal calcifications could be explained by a better renal function or a reduced muscle mass. From a physiological point of view, a higher creatinine clearance in stone formers would increase the renal filtered calcium load independent of plasma calcium and thereby increase the tendency towards hypercalciuria. The renal TRCa\% could theoretically influence this tendency, but we found no difference between the groups in TRCa. However, the lack of significant differences in these variables between the two groups preclude any final conclusion regarding the relationship between low plasma creatinine and renal calcifications. This may

Table 4 Biochemical parameters of significance to presence of renal stones vs nephrocalcinosis. Mutually adjusted in a logistic regression analysis.

\begin{tabular}{lrc}
\hline Variable & $\begin{array}{c}\text { Regression coefficient } \\
\text { (mean } \pm \text { S.E.M.) }\end{array}$ & $\boldsymbol{P}$ \\
\hline Alkaline phosphatase & $0.01 \pm 0.03$ & 0.64 \\
Creatinine & $-0.01 \pm 0.06$ & 1.00 \\
Urine calcium & $0.85 \pm 0.53$ & 0.11 \\
Urine creatinine & $0.05 \pm 0.04$ & 0.22 \\
lonised calcium & $1.11 \pm 9.37$ & 0.91 \\
25OHD & $-0.01 \pm 0.02$ & 0.88 \\
Calcitriol & $0.02 \pm 0.02$ & 0.31 \\
Phosphate & $3.26 \pm 6.06$ & 0.59 \\
PTH & $-0.26 \pm 0.35$ & 0.45 \\
\hline
\end{tabular}

25OHD, plasma 25-hydroxyvitamin D; PTH, plasma parathyroid hormone. 
be due to a type 2 error underlining the need of more statistical power to solve this question.

The renal calcium/creatinine excretion rate $(\mathrm{CaE})$ was increased in our PHPT patients with renal calcifications compared with those without calcifications. This supports that the renal calcium excretion rate may be a risk factor for renal calcifications. There was no significant difference in 24-h calcium excretion between the groups, although the average value was higher in stone formers than in non-stone formers. However, CaE may be a better measure of calcium excretion because it, to some extent, adjusts for urine collection errors and individual differences in body size (33).

The average plasma calcium level tended to be relatively high in the present population compared with other studies (24), although at the same level as in other Danish series $(34,35)$. This may be explained in several ways. One possibility is a general diagnostic delay in Denmark. Another explanation could be that we insist that the patients are demonstrably hypercalcaemic to undergo surgery, such as the present population has done. Finally, we usually do not recognise the term normocalcaemic hyperparathyroidism. Study populations may therefore not be comparable. In a steady state situation with respect to plasma calcium, renal calcium excretion reflects the amount of calcium absorbed from the gut and lost from the skeleton. In our study, we found a borderline significant increase in plasma $1,25(\mathrm{OH})_{2} \mathrm{D}$ in stone formers compared with non-stone formers.

We did not find any significant difference between groups in any of the other variables. In accordance with a previous study (29), we found no difference between groups in p-250HD, although low vitamin D status may be associated with higher PTH levels in PHPT and a more severe clinical presentation $(13,29,36)$.

The biochemical variables seemed to be unreliable in the prediction of renal stones in PHPT patients. Therefore, we cannot recommend using neither single nor multiple biochemical parameters in screening for renal stones. This is in accordance with the previous findings $(26,29)$. A recent larger clinical review could not identify any factors that increased the risk of renal calcification (beside male gender and young age) but concluded that CT scanning is the best way to diagnose nephrolithiasis (25). This is in accordance with our findings.

Previous studies have not addressed any differences between renal calcifications and frank renal stones. In our study, renal stones were more common in younger individuals. Renal stones are also most often observed in younger non-PHPT individuals $(4,37)$, although some report differently (1). Hence, our finding could just be explained by an increased risk of renal stones with young age in the general population.

\section{Limitations to study}

The included patients in this study represent all patients diagnosed with PHPT in the Central Denmark Region in 2007-2009. This eliminates most kinds of inclusion biases. On the other hand, 68 patients were excluded because of missing CT scans and a variable number of patients were excluded because of missing blood/urine samples. It was not investigated whether these excluded patient groups differ from the final cohort, which makes this a possible source of error. Another group of patients were excluded because they were not found to fulfil the criteria of PHPT. This should not have influenced the results of the study.

This is a historic cohort study. However, bias may be reduced by the fact that all data were collected independently of the aim of this study. Furthermore, all medical and surgical records were retrieved and adjudicated by two researchers (J Starup-Linde, E Waldhauer) at the time of study. Potential disagreements were resolved by consensus. Surgery was performed at a single surgical department specialised in parathyroid surgery. In all cases, the diagnosis of PHPT was confirmed by a histopathological examination of the removed tissue. Patients with $\mathrm{FHH}$ that may mimic PHPT were thoroughly excluded by routine determination of the calcium/creatinine clearance ratio and a CASR gene test in suspected cases $(30,38)$. Furthermore, the population in the region is primarily Caucasian, which makes the cohort homogeneous. Finally, the number included in our study is to our knowledge the largest in a study dealing with PHPT and renal calcification.

\section{Conclusion}

We found a high prevalence of renal calcifications (25.4\%) among PHPT patients without deterioration of renal function. The occurrence of calcifications was related to low plasma creatinine and a high urine calcium/creatinine ratio. However, biochemical markers in general were poor predictors of the presence of renal calcifications, indicating that routine image diagnostics by CT scan may be needed for the identification of these in order to ensure proper treatment and to set the indication for surgery.

\section{Declaration of interest}

The authors declare that there is no conflict of interest that could be perceived as prejudicing the impartiality of the research reported.

\section{Funding}

This research did not receive any specific grant from any funding agency in the public, commercial or not-for-profit sector. 


\section{Acknowledgements}

The authors are grateful for the assistance of research librarian Ms Edith Clausen.

\section{References}

1 Knoll T, Schubert AB, Fahlenkamp D, Leusmann DB, Wendt-Nordahl G \& Schubert G. Urolithiasis through the ages: data on more than 200,000 urinary stone analyses. Journal of Urology 2011185 1304-1311. (doi:10.1016/j.juro.2010.11.073)

2 Fraser WD. Hyperparathyroidism. Lancet 2009374 145-158. (doi:10.1016/S0140-6736(09)60507-9)

3 Vestergaard P \& Mosekilde L. Incidens af primær hyperparatyroidisme, hyppighed af operation og mortalitet belyst ved data fra Landspatientregistret. Ugeskrift for Laeger 2004166 41-45.

4 Turney BW, Reynard JM, Noble JG \& Keoghane SR. Trends in urological stone disease. BJU International 2012109 1082-1087. (doi:10.1111/j.1464-410X.2011.10495.x)

5 Siilin H, Lundgren E, Mallmin H, Mellstrom D, Ohlsson C, Karlsson M, Orwoll E \& Ljunggren O. Prevalence of primary hyperparathyroidism and impact on bone mineral density in elderly men: MrOs Sweden. World Journal of Surgery 201135 1266-1272. (doi:10.1007/s00268-011-1062-2)

6 Yu N, Donnan PT, Murphy MJ \& Leese GP. Epidemiology of primary hyperparathyroidism in Tayside, Scotland, UK. Clinical Endocrinology 200971 485-493. (doi:10.1111/j.1365-2265.2008. $03520 . x)$

7 Hackett DA \& Kauffman GL Jr. Historical perspective of parathyroid disease. Otolaryngologic Clinics of North America 200437 689-700, vii. (doi:10.1016/j.otc.2004.02.003)

8 Andersen P \& Mosekilde L. Tubular reabsorption of phosphate and calcium in primary hyperparathyroidism. Acta Medica Scandinavica $1972191565-572$.

9 Khosla S. Minireview: the OPG/RANKL/RANK system. Endocrinology 2001142 5050-5055. (doi:10.1210/en.142.12.5050)

10 Parks JH, Coe FL, Evan AP \& Worcester EM. Clinical and laboratory characteristics of calcium stone-formers with and without primary hyperparathyroidism. BJU International 2009 103 670-678. (doi:10.1111/j.1464-410X.2008.08064.x)

11 Mosekilde L. Primary hyperparathyroidism and the skeleton. Clinical Endocrinology 200869 1-19. (doi:10.1111/j.1365-2265. 2007.03162.x)

12 Parfitt AM. The actions of parathyroid hormone on bone: relation to bone remodeling and turnover, calcium homeostasis, and metabolic bone diseases. II. PTH and bone cells: bone turnover and plasma calcium regulation. Metabolism: Clinical and Experimental 197625 909-955. (doi:10.1016/0026-0495(76)90124-4)

13 Moosgaard B, Christensen SE, Vestergaard P, Heickendorff L, Christiansen P \& Mosekilde L. Vitamin D metabolites and skeletal consequences in primary hyperparathyroidism. Clinical Endocrinology 200868 707-715. (doi:10.1111/j.1365-2265.2007. 03109.x)

14 Perez AV, Picotto G, Carpentieri AR, Rivoira MA, Peralta Lopez ME \& Tolosa de Talamoni NG. Minireview on regulation of intestinal calcium absorption. Emphasis on molecular mechanisms of transcellular pathway. Digestion 200877 22-34. (doi:10.1159/ 000116623)

15 Dusso AS, Brown AJ \& Slatopolsky E. Vitamin D. American Journal of Physiology. Renal Physiology 2005 289 F8-F28. (doi:10. 1152/ajprenal.00336.2004)

16 Park S \& Pearle MS. Pathophysiology and management of calcium stones. Urologic Clinics of North America 200734 323-334. (doi:10.1016/j.ucl.2007.04.009)

17 Odvina CV, Sakhaee K, Heller HJ, Peterson RD, Poindexter JR, Padalino PK \& Pak CY. Biochemical characterization of primary hyperparathyroidism with and without kidney stones. Urological Research 200735 123-128. (doi:10.1007/s00240-007-0096-2)
18 Suh JM, Cronan JJ \& Monchik JM. Primary hyperparathyroidism: is there an increased prevalence of renal stone disease? AJR. American Journal of Roentgenology $2008191908-911$. (doi:10.2214/AJR.07.3160)

19 Pak CY, Nicar MJ, Peterson R, Zerwekh JE \& Snyder W. A lack of unique pathophysiologic background for nephrolithiasis of primary hyperparathyroidism. Journal of Clinical Endocrinology and Metabolism 1981 53 536-542. (doi:10.1210/jcem-53-3-536)

20 Soreide JA, van Heerden JA, Grant CS, Lo CY \& Ilstrup DM. Characteristics of patients surgically treated for primary hyperparathyroidism with and without renal stones. Surgery $1996 \mathbf{1 2 0}$ 1033-1037 (discussion 1037-8). (doi:10.1016/S00396060(96)80051-1)

21 Frokjaer VG \& Mollerup CL. Primary hyperparathyroidism: renal calcium excretion in patients with and without renal stone disease before and after parathyroidectomy. World Journal of Surgery 2002 26 532-535. (doi:10.1007/s00268-001-0262-6)

22 Mollerup CL \& Lindewald H. Renal stones and primary hyperparathyroidism: natural history of renal stone disease after successful parathyroidectomy. World Journal of Surgery 199923 173-175 (discussion 176). (doi:10.1007/PL00013175)

23 Mollerup CL, Vestergaard P, Frokjaer VG, Mosekilde L, Christiansen P \& Blichert-Toft M. Risk of renal stone events in primary hyperparathyroidism before and after parathyroid surgery: controlled retrospective follow up study. BMJ $2002 \mathbf{3 2 5}$ 807. (doi:10.1136/bmj.325.7368.807)

24 Wu B, Haigh PI, Hwang R, Ituarte PH, Liu IL, Hahn TJ \& Yeh MW. Underutilization of parathyroidectomy in elderly patients with primary hyperparathyroidism. Journal of Clinical Endocrinology and Metabolism 2010 95 4324-4330. (doi:10.1210/jc.2009-2819)

25 Rejnmark L, Vestergaard P \& Mosekilde L. Nephrolithiasis and renal calcifications in primary hyperparathyroidism. Journal of Clinical Endocrinology and Metabolism 201196 2377-2385. (doi:10.1210/jc.2011-0569)

26 Berger $\mathrm{AD}, \mathrm{Wu} \mathrm{W}$, Eisner BH, Cooperberg MR, Duh QY \& Stoller ML. Patients with primary hyperparathyroidism - why do some form stones? Journal of Urology $2009 \mathbf{1 8 1} 2141-2145$. (doi:10.1016/j.juro.2009.01.028)

27 D’Angelo A, Lodetti MG, Giannini S, Castrignano R, al Awady M, Malvasi L, Fabris A \& Maschio G. Hyperparathyroidism: cause or consequence of recurrent calcium nephrolithiasis? Mineral and Electrolyte Metabolism 199218 359-364.

28 Sakhaee K, Poindexter JR, Griffith CS \& Pak CY. Stone forming risk of calcium citrate supplementation in healthy postmenopausal women. Journal of Urology 2004172 958-961. (doi:10.1097/01. ju.0000136400.14728.cd)

29 Bandeira F, Caldas G, Freese E, Griz L, Faria M \& Bandeira C. Relationship between serum vitamin D status and clinical manifestations of primary hyperparathyroidism. Endocrine Practice 20028 266-270.

30 Christensen SE, Nissen PH, Vestergaard P, Heickendorff L, Brixen K \& Mosekilde L. Discriminative power of three indices of renal calcium excretion for the distinction between familial hypocalciuric hypercalcaemia and primary hyperparathyroidism: a follow-up study on methods. Clinical Endocrinology 200869 713-720. (doi:10.1111/j.1365-2265.2008.03259.x)

31 Souberbielle JC, Lawson-Body E, Hammadi B, Sarfati E, Kahan A \& Cormier $\mathrm{C}$. The use in clinical practice of parathyroid hormone normative values established in vitamin D-sufficient subjects. Journal of Clinical Endocrinology and Metabolism 2003 88 3501-3504. (doi:10.1210/jc.2003-030097)

32 Hojskov CS, Heickendorff L \& Moller HJ. High-throughput liquid-liquid extraction and LCMSMS assay for determination of circulating $25(\mathrm{OH})$ vitamin D3 and D2 in the routine clinical laboratory. Clinica Chimica Acta $2010 \mathbf{4 1 1} 114-116$. (doi:10.1016/j.cca.2009.10.010)

33 Heymsfield SB, Arteaga C, McManus C, Smith J \& Moffitt S. Measurement of muscle mass in humans: validity of the 24-hour urinary creatinine method. American Journal of Clinical Nutrition $198337478-494$. 
34 Mollerup CL, Bollerslev J \& Blichert-Toft M. Primary hyperparathyroidism: incidence and clinical and biochemical characteristics. A demographic study. European Journal of Surgery 1994 $160485-489$.

35 Vestergaard P, Mollerup CL, Frokjaer VG, Christiansen PM, Blichert-Toft M \& Mosekilde L. Cohort study of fracture risk before and after surgery of primary hyperparathyroidism. Ugeskrift for Laeger $2001 \mathbf{1 6 3} 4875-4878$.

36 Moosgaard B, Vestergaard P, Heickendorff L \& Mosekilde L. Plasma 1,25-dihydroxyvitamin D levels in primary hyperparathyroidism depend on sex, body mass index, plasma phosphate and renal function. Clinical Endocrinology 200766 35-42.
37 Stamatelou KK, Francis ME, Jones CA, Nyberg LM \& Curhan GC. Time trends in reported prevalence of kidney stones in the United States: 1976-1994. Kidney International 200363 1817-1823. (doi:10.1046/j.1523-1755.2003.00917.x)

38 Christensen SE, Nissen PH \& Schwarz P. Investigation and diagnosis of familial hypocalciuric hypercalcemia in Denmark. Ugeskrift for Laeger 2005167 905-910.

Received 13 January 2012

Revised version received 22 March 2012

Accepted 3 April 2012 